\title{
Amino acid-incorporated polymer network by thiol-ene polymerization
}

\author{
R. Yokose, T. Shimasaki, N. Teramoto, M. Shibata* \\ Department of Life and Environmental Sciences, Faculty of Engineering, Chiba Institute of Technology, 2-17-1, \\ Tsudanuma, Narashino, 275-0016 Chiba, Japan
}

Received 22 January 2015; accepted in revised form 9 March 2015

\begin{abstract}
Triallyl L-alanine (A3A) and triallyl L-phenylalanine (A3F) were synthesized by reactions of L-alanine and L-phenylalanine with allyl bromide in the presence of sodium hydroxide, respectively. Thiol-ene thermal polymerization of A3A or A3F with pentaerythritol-based primary tetrathiol (pS4P) or pentaerythritol-based secondary tetrathiol (S4P) at allyl/SH 1/1 in the presence of 2,2'-azobis(isobutyronitrile) produced an amino acid-incorporated polymer network (A3ApS4P, A3A-S4P or A3F-S4P). Although the thermally cured resins were homogeneous and flat films, the corresponding thiol-ene photopolymerization did not give a successful result. Degree of swelling for each thermally cured film in $N, N$ dimethylformamide was much higher than that in water. The glass transition and 5\% weight loss temperatures $\left(T_{\mathrm{g}}\right.$ and $\left.T_{5}\right)$ of A3F-pS4P and A3F-S4P were higher than those of A3A-pS4P and A3A-S4P, respectively. Also, A3F-pS4P and A3F-S4P exhibited much higher tensile strengths and moduli than A3A-pS4P and A3A-S4P did, respectively. Consequently, A3FpS4P displayed the highest $T_{\mathrm{g}}\left(38.7^{\circ} \mathrm{C}\right), T_{5}\left(282.0^{\circ} \mathrm{C}\right)$, tensile strength $(9.5 \mathrm{MPa})$ and modulus $(406 \mathrm{MPa})$ among all the thermally cured resins.
\end{abstract}

Keywords: thermosetting resins, biopolymers, alanine, phenylalanine, thiol-ene polymerization

\section{t1. Introduction}

Naturally occurring $\alpha$-amino acid based polymers have gathered considerable attention over recent years as biodegradable, biocompatible and functional materials having various characteristics such as amphoteric nature [1, 2], chiral recognition [3], drug delivery $[4,5]$, response to stimuli [6-12] and self-organization via supramolecular interactions [13-15]. In past studies, amino acid-based side chain polymers had been mainly synthesized by conventional or controlled free radical polymerizations of amino acids whose $\mathrm{N}$ - or $\mathrm{C}$-terminals are modified with (meth)acrylamide $[1-4,10-12,14$, 16-22] or (meth)acrylate groups [6-9, 23-27]. Amino acid-based main chain polymers had been prepared by ring-opening polymerizations of $\alpha$ - amino acid $N$-carboxyanhydrides $[15,28-30]$ or polycondensations of amino acids [31,32]. Although these strategies had been successfully applied to the synthesis of linear polymers having amino acid moieties, the polymer networks having amino acid moieties in the main chain have not yet been synthesized by the addition polymerizations of amino acids whose $N$ - and $C$-terminals are simultaneously modified with substituted olefinic groups. There have been few reports on the synthesis of amino acidbased polymer networks by use of polyaddition reactions. For example, Kiyotsukuri et al. [33] reported a polymer network by the reaction of lysine triisocyanate and glutamic acid diethylester hydrochloride. Li et al. [34] reported a polymer network by the reaction of a cycloaliphatic epoxy resin with

$\overline{{ }^{*} \text { Corresponding author, e-mail: mitsuhiro.shibata@p.chibakoudai.jp }}$ (C) BME-PT 
DL-lysine, or diglycidyl ether of bisphenol A with L-tryptophan [35]. We also reported a polymer network by the reaction of 4,4'-bismaleimidodiphenylmethane with L-lysine [36].

Recently, radical-mediated thiol-ene 'click' reactions have attracted increasing attention as a method for the production of crosslinked polymer networks with various frameworks and functional groups [37-40]. The radical thiol-ene reaction can be initiated by a variety of techniques including under traditional thermal conditions with common azo species such as $2,2^{\prime}$-azobis(isobutyronitrile) (AIBN) or via photochemical methods, with or without added photoinitiator. Thiol-ene polymerization is characterized by advantages such as an inherently rapid reaction rate, reduced oxygen inhibition, high regioselectivity and low polymerization shrinkage. Furthermore, as the reaction is initiated by the formation of primary radicals by the decomposition of an initiator and subsequent production of a thiyl radical by the abstraction of a hydrogen radical from the thiol group, monomers containing functional groups $\left(\mathrm{OH}, \mathrm{CO}_{2} \mathrm{H}, \mathrm{NH}_{2}\right.$ etc.) with a hydrogen that is less easily abstracted than the hydrogen of a thiol group can be polymerized without protecting the functional groups. In past studies, several research groups reported on the syntheses of bio-based polymer networks by thiol-ene polymerizations. For example, Echeverri et al. [41] reported elastomeric networks from maleated soybean-oil glycerides by thiol-ene coupling. Ortiz et al. [42] reported polymer networks prepared by thiol-ene photopolymerizations of allyl-etherified sucroses. We also reported trehalose- and eugenol-incorpolated polymer networks by thiol-ene photopolymerizations [43, 44]. In the past studies, thiol-ene reactions have been applied to the modification of unsaturated amino acids [45] and to the synthesis of peptide-functionalized conjugates [46], but amino acid-based polymer network has not been prepared by use of thiolene polymerization to the best of our knowledge. In this study, triallyl L-alanine (A3A) and triallyl Lphenylalanine (A3F) whose $N$ - and $C$-terminals are simultaneously modified with allyl groups were conveniently synthesized by one-pot reactions of Lalanine and L-phenylalanine with allyl bromide, respectively (Figure 1), and thermal and mechanical properties of polymer networks prepared by thiol-ene reactions of $\mathrm{A} 3 \mathrm{~A}$ and $\mathrm{A} 3 \mathrm{~F}$ with tetrathiol compounds were investigated.

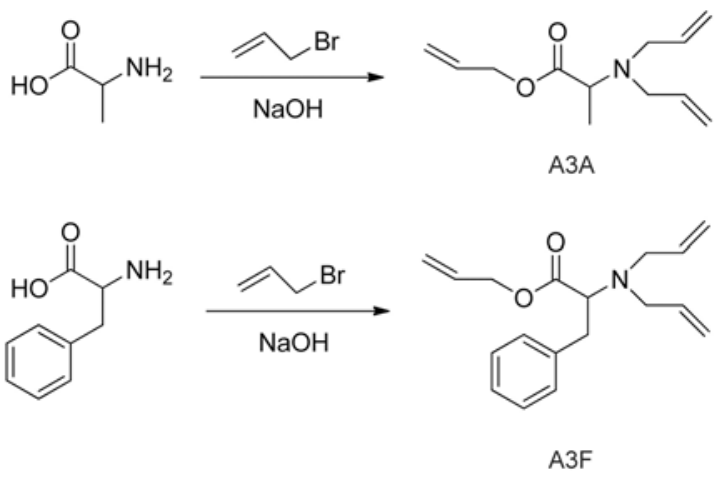

Figure 1. Synthesis of A3A and A3F

\section{Experimental section \\ 2.1. Materials}

L-Alanine and L-phenylalanine were purchased from Tokyo Kasei Kogyo Co. Ltd. (Tokyo, Japan). Pentaerythritol-based primary tetrathiol (pS4P, pentaerythritol tetrakis(3-mercaptopropionate)) was purchased from Sigma-Aldrich Corporation (St. Louis, MO, USA). Pentaerythritol-based secondary tetrathiol (S4P, pentaerythritol tetrakis(3-mercaptobutyrate), trade name: Karenz MTTM PE1) was kindly provided by Showa Denko K. K. (Tokyo, Japan). The chemical structures of pS4P and S4P are shown in Figure 2. As photo-initiators, 1-hydroxycyclohexyl phenyl ketone (Irgacure ${ }^{\circledR} 184, \mathrm{mp} .45-49^{\circ} \mathrm{C}$, UV/VIS absorption peaks in methanol: 246, 280, $333 \mathrm{~nm}$ ), phenyl bis(2,4,6-trimethylbenzoyl) phosphine oxide (Irgacure ${ }^{\circledR} 819$, mp. $127-133^{\circ} \mathrm{C}$, UV/VIS absorption peaks in methanol: $295,370 \mathrm{~nm}$ ), 2hydroxy-1-[4-(2-hydroxyethoxy)phenyl]-2-methyl1-propanone (Irgacure ${ }^{\circledR} 2959$, mp. 86.5-89.5 ${ }^{\circ} \mathrm{C}$, UV/VIS absorption peak in methanol: $276 \mathrm{~nm}$ ) were purchased from Toyotsu Chemiplas Corporation (Tokyo, Japan). ( \pm )-Camphorquinone (Wako Pure Chemical Industries Ltd., Osaka, Japan) was also used as a photo-initiator. Allyl bromide, sodium hydroxide, AIBN, dimethyl sulfoxide (DMSO), $\mathrm{N}, \mathrm{N}$-dimethylformamide (DMF) and acetone were purchased from Kanto Chemical Co., Inc. (Tokyo,
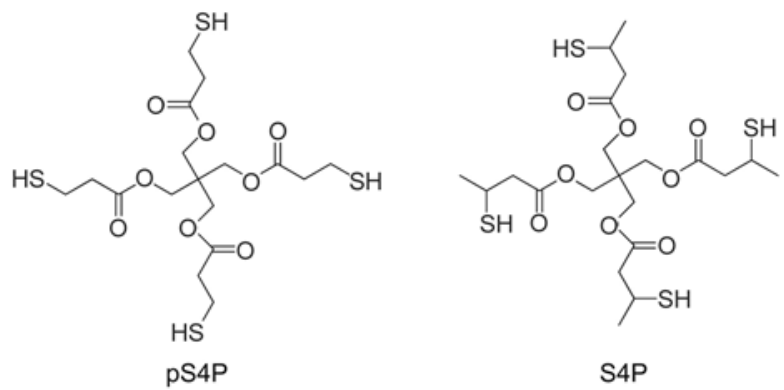

Figure 2. Chemical structures of pS4P and S4P 
Japan). All of the commercially available reagents were used without further purification.

\subsection{Synthesis of $\mathrm{N}, \mathrm{N}, \mathrm{O}$-triallyl-L-alanine (A3A)}

To a solution of L-alanine $(0.891 \mathrm{~g}, 10.0 \mathrm{mmol})$ in DMSO $(30 \mathrm{~mL})$, pulverized sodium hydroxide $(2.64 \mathrm{~g}, 66.0 \mathrm{~mol})$ was added, and the resulting mixture was stirred for $10 \mathrm{~min}$. Allyl bromide $(3.99 \mathrm{~g}$, $33.0 \mathrm{~mol}$ ) was dropwise added over a period of $30 \mathrm{~min}$ at room temperature. After the addition, the mixture was stirred for $24 \mathrm{~h}$ at room temperature and filtered. Dilute hydrochloric acid was added to the filtrate, and then extracted with chloroform. The organic layer was washed with water five times, dried over sodium sulfate and concentrated in vacuo to produce $\mathrm{A} 3 \mathrm{~A}$ as a brown liquid $(1.08 \mathrm{~g})$ in $52 \%$ yield: ${ }^{13} \mathrm{C}-\mathrm{NMR}\left(400 \mathrm{MHz}, \mathrm{CDCl}_{3}, \delta\right.$, ppm): 14.94 (C-9), 53.63 (C-4), 57.38 (C-7), 64.76 (C-1), 116.87 (C-6), 118.24 (C-3), 132.17 (C-2), 136.41 (C-5), 173.52 (C-8). Anal. calcd. for $\mathrm{C}_{12} \mathrm{H}_{19} \mathrm{O}_{2} \mathrm{~N}$ : C, $68.87 \%$; H, 9.15\%; N, 6.69\%. Found: C, 68.5\%; H, $9.22 \% ; \mathrm{N}, 6.30 \%$.

\subsection{Synthesis of \\ $\mathrm{N}, \mathrm{N}, \mathrm{O}$-triallyl-L-phenylalanine (A3F)}

To a solution of L-phenylalanine $(1.65 \mathrm{~g}, 10.0 \mathrm{mmol})$ in DMSO $(30 \mathrm{~mL})$, pulverized sodium hydroxide ( $2.64 \mathrm{~g}, 66.0 \mathrm{~mol})$ was added, and the resulting mixture was stirred for $10 \mathrm{~min}$. Allyl bromide $(3.99 \mathrm{~g}$, $33.0 \mathrm{~mol}$ ) was dropwise added over a period of $30 \mathrm{~min}$ at room temperature. After the addition, the mixture was stirred for $24 \mathrm{~h}$ at room temperature and filtered. Dilute hydrochloric acid was added to the filtrate, and then extracted with ethyl acetate. The organic layer was washed with water three times, dried over sodium sulfate and concentrated in vacuo to produce $\mathrm{A} 3 \mathrm{~F}$ as a brown liquid (2.62 $\mathrm{g}$ ) in $92 \%$ yield. ${ }^{13} \mathrm{C}$-NMR $\left(400 \mathrm{MHz}, \mathrm{CDCl}_{3}, \delta\right.$, ppm): 35.96 (C-9), 53.54 (C-4), 64.05 (C-7), 64.95 (C-1), 117.07 (C-6), 118.22 (C-3), 126.45 (C-13), 128.05 (C-12), 129.32 (C-11), 132.10 (C-2), 136.19 (C-5), 138.83 (C-10), 172.16 (C-8). Anal. calcd. for $\mathrm{C}_{18} \mathrm{H}_{23} \mathrm{O}_{2} \mathrm{~N}$ : C, 75.76\%; H, 8.12\%; N, 4.91\%. Found: C, 75.4\%; $\mathrm{H}, 8.09 \%$;, $4.91 \%$.

\subsection{Thiol-ene photopolymerization of A3A and $\mathrm{pS} 4 \mathrm{P}$}

A mixture of A3A (0.209 g, $1.00 \mathrm{mmol}), \mathrm{pS} 4 \mathrm{P}$ $(0.366 \mathrm{~g}, 0.750 \mathrm{mmol})$, IRGACURE $^{\circledR} 2959(17 \mathrm{mg}$, $0.076 \mathrm{mmol})$ and acetone $(2 \mathrm{~mL})$ was stirred for
$30 \mathrm{~min}$ to form a homogeneous solution. The solution was poured on a glass culture dish with a diameter of $40 \mathrm{~mm}$ and was dried at $60^{\circ} \mathrm{C}$ for $3 \mathrm{~h}$. The obtained mixture was photo-irradiated for $30 \mathrm{~s} \times$ 60 times at $1 \mathrm{~min}$ intervals to yield a photo-cured $\mathrm{A} 3 \mathrm{~A} / \mathrm{pS} 4 \mathrm{P}$ with the allyl/SH ratio of $1 / 1$ (pc-A3ApS4P) film with wrinkles. A SPOT-CURE SP-7 (250 W light source, wavelength $240-440 \mathrm{~nm}$, Ushio Inc., Yokohama, Japan) device equipped with a uniform-radiation optical unit was used for UV curing (irradiation distance $200 \mathrm{~mm}$, irradiation intensity $72 \mathrm{~mW} / \mathrm{cm}^{2}$ ).

\subsection{Thiol-ene thermal polymerizations}

A typical procedure is as follows: A mixture of A3A (2.233 g, $10.67 \mathrm{mmol})$, pS4P (3.909 g, $8.00 \mathrm{mmol})$, AIBN $(57 \mathrm{mg}, 0.35 \mathrm{mmol})$ and acetone $(5 \mathrm{~mL})$ was stirred for $30 \mathrm{~min}$ to form a homogeneous solution. The solution was poured on a poly(methylpentene) culture dish with a diameter of $85 \mathrm{~mm}$ and was dried at room temperature for $3 \mathrm{~h}$. The obtained mixture was cured at $80^{\circ} \mathrm{C}$ for $24 \mathrm{~h}$ and furthermore at $120^{\circ} \mathrm{C}$ for $48 \mathrm{~h}$ to yield a thermally cured A3A/ $\mathrm{pS} 4 \mathrm{P}$ with the allyl/SH ratio of 1/1 (A3A-pS4P) film (thickness: ca. $1.0 \mathrm{~mm}$ ).

In a manner similar to the preparation of A3A-pS4P except using A3F (2.282 g, $8.00 \mathrm{mmol}), \mathrm{pS} 4 \mathrm{P}$ (3.269 g, $6.00 \mathrm{mmol})$, AIBN (56 mg, $0.34 \mathrm{mmol})$ and acetone $(4 \mathrm{~mL})$, a thermally cured $\mathrm{A} 3 \mathrm{~F} / \mathrm{pS} 4 \mathrm{P}$ with the allyl/SH ratio of 1/1 (A3F-pS4P) film (thickness: ca. $1.0 \mathrm{~mm}$ ) were prepared. Thermally cured $\mathrm{A} 3 \mathrm{~A} / \mathrm{S} 4 \mathrm{P}$ and $\mathrm{A} 3 \mathrm{~F} / \mathrm{S} 4 \mathrm{P}$ with the allyl/SH ratio of 1/1 (A3A-S4P and A3F-S4P) were similarly prepared by using S4P instead of pS4P.

\subsection{Measurements}

Proton and carbon nuclear magnetic resonance $\left({ }^{1} \mathrm{H}\right.$ and ${ }^{13} \mathrm{C}$-NMR) spectra were recorded on a Bruker AV-400 (400 MHz) (Madison, WI, USA) using $\mathrm{CDCl}_{3}$ as a solvent. Fourier transform infrared (FTIR) spectra were recorded on a Shimadzu FT-IR 8100 (Kyoto, Japan) by the attenuated total reflectance (ATR) method. Elemental analyses were performed on a SUMIGRAPH NCH-22F elemental microanalyzer (Sumika Chemical Analysis Service, Ltd., Ehime, Japan). Degree of swelling $\left(D_{\mathrm{s}}\right)$ was measured by dipping a thermally cured film (length $10 \mathrm{~mm}$, width $10 \mathrm{~mm}$, thickness $1.0 \mathrm{~mm}$ ) in deionized water, acetone or DMF at room temperature for $48 \mathrm{~h}$ according to Equation (1): 
$D_{\mathrm{s}}[\%]=100 \frac{w_{1}-w_{0}}{w_{0}}$

where $w_{0}$ is the initial weight of the cured film and $w_{1}$ is the weight of the swollen film after dipping. The differential scanning calorimetry (DSC) measurements were performed on a Perkin-Elmer Diamond DSC (Waltham, MA, USA) in a nitrogen atmosphere. The samples were heated from -100 to $200^{\circ} \mathrm{C}$ at a heating rate of $20^{\circ} \mathrm{C} \cdot \mathrm{min}^{-1}$ to determine the glass transition temperature $\left(T_{\mathrm{g}}\right)$. The $5 \%$ weight loss temperature $\left(T_{5}\right)$ was measured on a Shimadzu TGA-50 thermogravimetric analyzer at a heating rate of $20^{\circ} \mathrm{C} \cdot \mathrm{min}^{-1}$ in a nitrogen atmosphere. Tensile testing of the rectangular plates (length $50 \mathrm{~mm}$, width $10 \mathrm{~mm}$, thickness $1.0 \mathrm{~mm}$ ) was performed at room temperature using a Shimadzu Autograph AG-1 based on the standard method for testing the tensile properties of plastics (JIS K7161:1994, ISO527-1). The span length was $25 \mathrm{~mm}$, and the testing speed was $10 \mathrm{~mm} \cdot \mathrm{min}^{-1}$. Five specimens were tested for each set of samples, and the mean value and standard deviation were calculated.

\section{Results and discussion}

\subsection{Synthesis and characterization of $A 3 A$} and $\mathbf{A} \mathbf{3 F}$

Triallylated amino acids, $\mathrm{A} 3 \mathrm{~A}$ and $\mathrm{A} 3 \mathrm{~F}$ whose all $\mathrm{N}$ - and $\mathrm{C}$-terminal active hydrogens are substituted by allyl groups were conveniently synthesized by
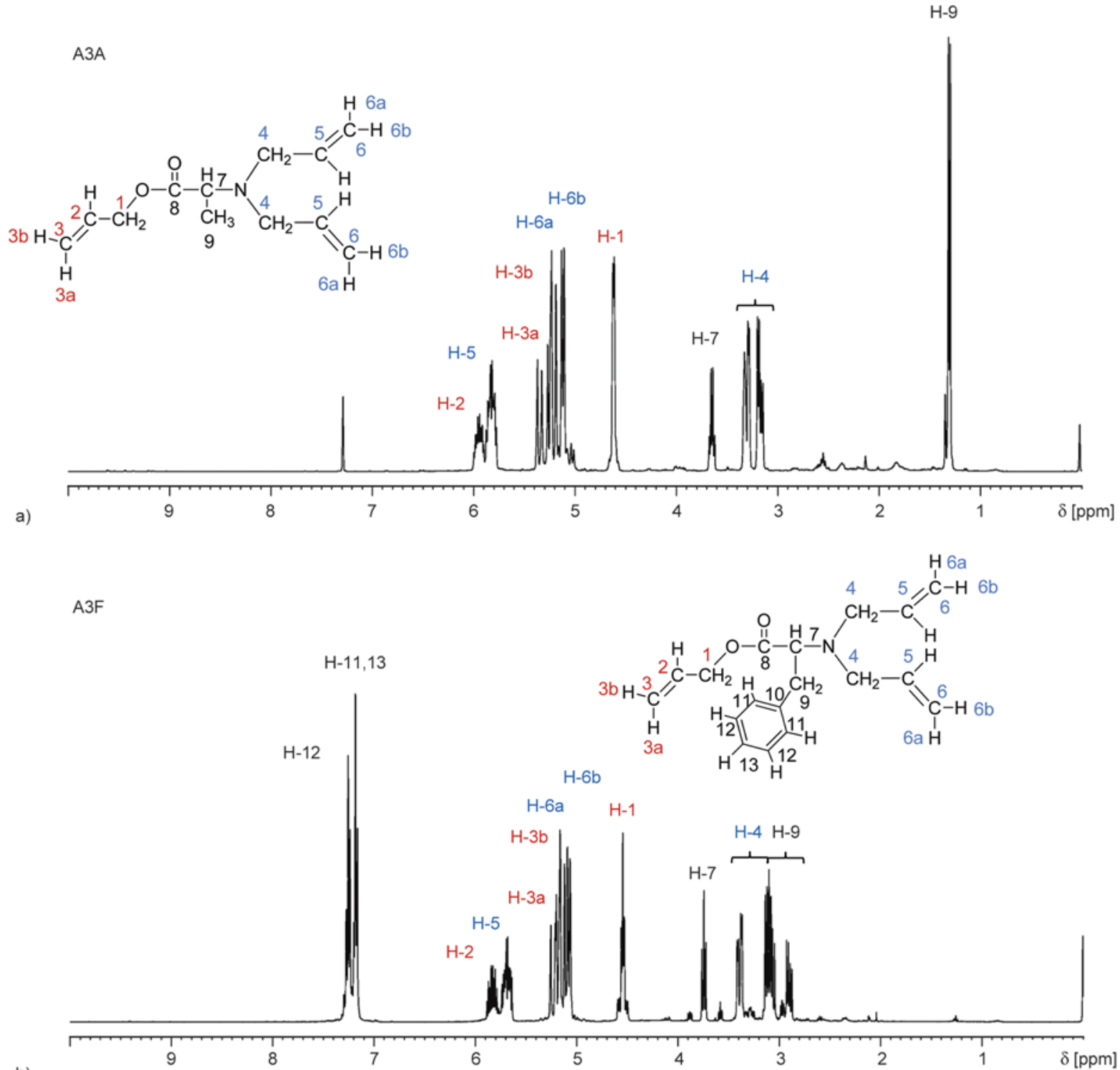

b)

Figure 3. ${ }^{1} \mathrm{H}-\mathrm{NMR}$ spectra of (a) A3A and (b) $\mathrm{A} 3 \mathrm{~F}$ in $\mathrm{CDCl}_{3}$. The ${ }^{1} \mathrm{H}$-signals displayed in red and blue are related $O$-allyl and $N$-allyl groups, respectively. 

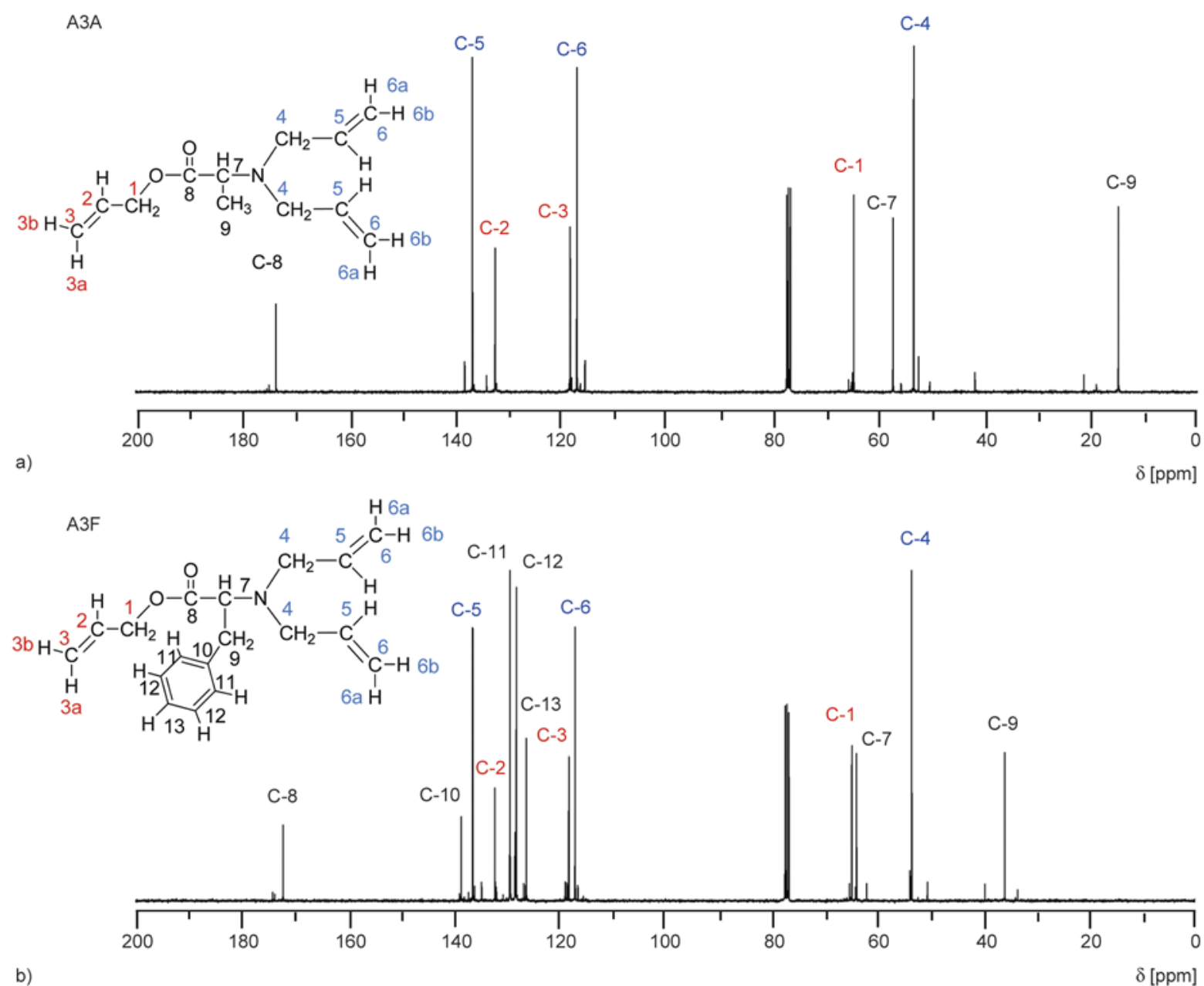

Figure 4. ${ }^{13} \mathrm{C}$-NMR spectra of (a) $\mathrm{A} 3 \mathrm{~A}$ and (b) $\mathrm{A} 3 \mathrm{~F}$ in $\mathrm{CDCl}_{3}$. The ${ }^{1} \mathrm{H}$-signals displayed in red and blue are related $O$-allyl and $N$-allyl groups, respectively.

reactions of L-alanine and L-phenylalanine with allyl bromide in the presence of excess pulverized sodium hydroxide in DMSO, respectively (Figure 1). Figure 3 a shows ${ }^{1} \mathrm{H}-\mathrm{NMR}$ spectrum of $\mathrm{A} 3 \mathrm{~A}$ in $\mathrm{CDCl}_{3}$. The methyl and methine ${ }^{1} \mathrm{H}$ signals of alanine residue of A3A were observed at $\delta 3.65(\mathrm{~m}$, $1 \mathrm{H}, \mathrm{H}-7)$ and $1.30 \mathrm{ppm}(\mathrm{d}, 3 \mathrm{H}, \mathrm{H}-9)$, respectively. The ${ }^{1} \mathrm{H}$ signals of $N, N$-diallyl groups were observed at $\delta 5.81(\mathrm{~m}, 2 \mathrm{H}, \mathrm{H}-5), 5.21(\mathrm{~m}, 2 \mathrm{H}, \mathrm{H}-6 \mathrm{a}), 5.11(\mathrm{~m}$, $2 \mathrm{H}, \mathrm{H}-6 \mathrm{~b})$ and $3.30,3.19 \mathrm{ppm}(\mathrm{m}, 4 \mathrm{H}, \mathrm{H}-4)$, respectively. The proton signals of $O$-allyl group were observed at $\delta 5.95(\mathrm{~m}, 1 \mathrm{H}, \mathrm{H}-2), 5.35(\mathrm{~m}, 1 \mathrm{H}, \mathrm{H}-$ 3a), 5.27 (m, 1H, H-3b) and $4.60 \mathrm{ppm}(\mathrm{m}, 2 \mathrm{H}, \mathrm{H}-1)$. Figure $3 \mathrm{~b}$ shows ${ }^{1} \mathrm{H}-\mathrm{NMR}$ spectrum of $\mathrm{A} 3 \mathrm{~F}$ in $\mathrm{CDCl}_{3}$. The phenyl, methine and benzyl methylene ${ }^{1} \mathrm{H}$ signals of phenylalanine residue of $\mathrm{A} 3 \mathrm{~F}$ were observed at $\delta 7.26(\mathrm{~m}, 2 \mathrm{H}, \mathrm{H}-12), 7.18(\mathrm{~m}, 3 \mathrm{H}, \mathrm{H}-$ 11,13), $3.75(\mathrm{~m}, 1 \mathrm{H}, \mathrm{H}-7)$ and 3.09, $2.90 \mathrm{ppm}(\mathrm{m}$, $2 \mathrm{H}, \mathrm{H}-9)$, respectively. The ${ }^{1} \mathrm{H}$ signals of $N, N$-diallyl groups were observed at $\delta 5.69(\mathrm{~m}, 2 \mathrm{H}, \mathrm{H}-5)$, $5.16(\mathrm{~m}, 2 \mathrm{H}, \mathrm{H}-6 \mathrm{a}), 5.06(\mathrm{~m}, 2 \mathrm{H}, \mathrm{H}-6 \mathrm{~b})$ and 3.39, $3.11 \mathrm{ppm}(\mathrm{m}, 4 \mathrm{H}, \mathrm{H}-4)$, respectively. The proton signals of $O$-allyl group were observed at $\delta 5.82(\mathrm{~m}$, $1 \mathrm{H}, \mathrm{H}-2), 5.26$ (m, 1H, H-3a), 5.20 (m, 1H, H-3b) and $4.52 \mathrm{ppm}(\mathrm{m}, 2 \mathrm{H}, \mathrm{H}-1)$. The fact that $\mathrm{N}-\mathrm{CH}_{2}$ protons $(\mathrm{H}-4$ of $\mathrm{A} 3 \mathrm{~A}$ or $\mathrm{A} 3 \mathrm{~F})$ were observed as complex signals indicates that the two methylene protons are magnetically non-equivalent probably due to steric hindrance around the $N$-methylene groups. Figure 4 shows ${ }^{13} \mathrm{C}-\mathrm{NMR}$ spectra of $\mathrm{A} 3 \mathrm{~A}$ and $\mathrm{A} 3 \mathrm{~F}$ in $\mathrm{CDCl}_{3}$. As are shown in the figure, all the carbons of $\mathrm{A} 3 \mathrm{~A}$ and $\mathrm{A} 3 \mathrm{~F}$ were reasonably assigned. The assignment of ${ }^{1} \mathrm{H}$ and ${ }^{13} \mathrm{C}$-signals of $\mathrm{A} 3 \mathrm{~A}$ and $\mathrm{A} 3 \mathrm{~F}$ shown in Figure 3 and Figure 4 was confirmed by $\mathrm{H}-\mathrm{H}$ correlated spectroscopy (COSY), $\mathrm{C}-\mathrm{H}$ COSY and the heteronuclear multiple bond correlation (HMBC) spectroscopy.

It is important for checking the progress of thiol-ene reaction of $\mathrm{A} 3 \mathrm{~A}$ and $\mathrm{A} 3 \mathrm{~F}$ to assign the IR absorption bands related to the allyl groups. Figure 5 shows 

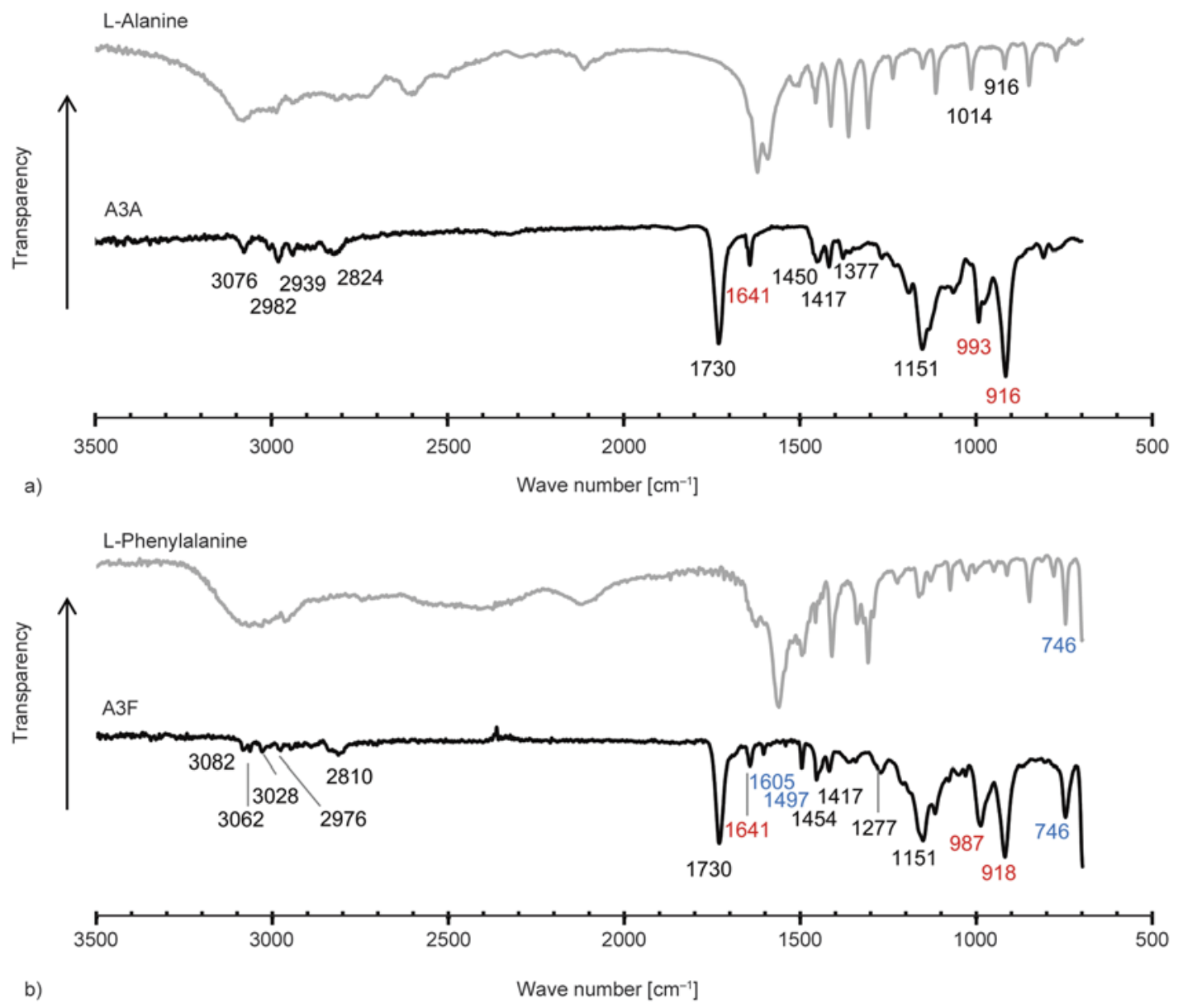

Figure 5. FT-IR spectra of (a) L-alanine and A3A and (b) L-phenylalanine and A3F. The wavenumbers displayed in red and blue are related to allyl and phenyl groups, respectively.

FT-IR spectra of A3A and A3F compared with those of L-alanine and L-phenylalanine. In the FT-IR spectrum of $\mathrm{A} 3 \mathrm{~F}$, the bands characteristic to benzene ring were observed at 1605,1497 and $746 \mathrm{~cm}^{-1}$, which are ascribed to aromatic $\mathrm{C}=\mathrm{C}$ stretching vibration and aromatic $=\mathrm{C}-\mathrm{H}$ out-of-plane bending vibration, respectively. As the bands which are common in the spectra of $\mathrm{A} 3 \mathrm{~A}$ and $\mathrm{A} 3 \mathrm{~F}$, the bands due to olefinic and/or aromatic $\mathrm{C}-\mathrm{H}$ stretching vibrations and aliphatic $\mathrm{C}-\mathrm{H}$ stretching vibration were observed at $3082-3028 \mathrm{~cm}^{-1}$ and $2982-2810 \mathrm{~cm}^{-1}$, respectively. Also, the bands due to $\mathrm{C}=\mathrm{O}$ and $\mathrm{C}-\mathrm{O}(\mathrm{C}-\mathrm{N})$ stretching vibrations were observed at 1730 and $1151 \mathrm{~cm}^{-1}$, respectively. Furthermore, the bands ascribed to allyl $\mathrm{C}=\mathrm{C}$ stretching $\left(v_{\mathrm{C}=\mathrm{C}}\right)$ and $=\mathrm{C}-\mathrm{H}$ out-of-plane bending $\left(\delta_{=\mathrm{C}-\mathrm{H}}\right)$ vibrations were observed at $1641 \mathrm{~cm}^{-1}$ and 993 (987), 916 (918) $\mathrm{cm}^{-1}$, respectively. These bands characteristic to allyl group were used for the confirmation of progress of thiol-ene reaction of $\mathrm{A} 3 \mathrm{~A}$ and $\mathrm{A} 3 \mathrm{~F}$ with the proviso that a weak absorption band is also observed at $916 \mathrm{~cm}^{-1}$ for L-alanine.

\subsection{FT-IR analysis for the thiol-ene polymerization of $\mathrm{A} 3 \mathrm{~A}$ and $\mathrm{A} 3 \mathrm{~F}$}

Thiol-ene photopolymerization of A3A and pS4P at the allyl/thiol ratio of $1 / 1$ in the presence of a photoinitiator (Irgacure ${ }^{\circledR} 184$ ) produced a crosslinked yellow film (pc-A3A-pS4P) with many wrinkles, as is obvious from Figure 6. Although other photoinitiators (Irgacure ${ }^{\circledR} 819$, Irgacure ${ }^{\circledR} 2959$ and camphorquinone) were examined, we could not get a flat film. Furthermore, photo-irradiation of a mixture of $\mathrm{A} 3 \mathrm{~F} / \mathrm{pS} 4 \mathrm{P}$ in the presence of a photoinitiator produced a viscous liquid whose surface portion only is hardened. There is a possibility that the sterically hindered diallylamino groups of $\mathrm{A} 3 \mathrm{~A}$ and $\mathrm{A} 3 \mathrm{~F}$ have a lower reactivity than the allyl ester group at room temperature. Next, thiol-ene thermal polymerizations were examined. When $\mathrm{A} 3 \mathrm{~A}$ and $\mathrm{A} 3 \mathrm{~F}$ were 
thermally cured with $\mathrm{pS} 4 \mathrm{P}$ in the presence of AIBN at $80-120^{\circ} \mathrm{C}$, flat and flexible films (A3A-pS4P and

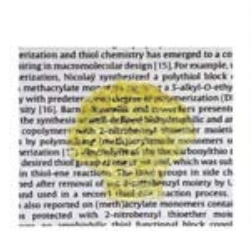

pc-A3A-pS4P

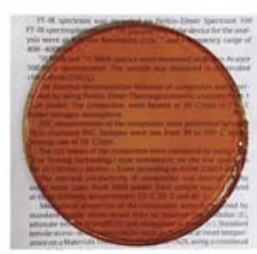

A3A-pS4P

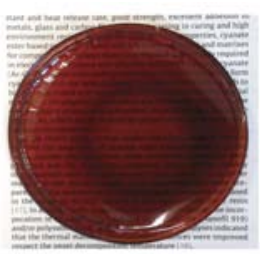

A3F-pS4P
Figure 6. Photographs of pc-A3A-pS4P, A3A-pS4P and A3F-pS4P films
A3F-pS4P) with a brown color were obtained (Figure 6). Also, we could get similar flat films by the thiol-ene thermal polymerizations of $\mathrm{A} 3 \mathrm{~A}$ and $\mathrm{A} 3 \mathrm{~F}$ with S4P. Also, we confirmed that A3A or A3F by itself cannot be thermally cured in the presence of AIBN at the same curing condition.

Figure 7 shows FT-IR spectra of pc-A3A-pS4P, A3A-pS4P and A3A-S4P compared with those of A3A, pS4P and S4P. The absorption bands related to allyl $v_{\mathrm{C}=\mathrm{C}}\left(1641 \mathrm{~cm}^{-1}\right)$ and $\delta_{=\mathrm{C}-\mathrm{H}}\left(993,916 \mathrm{~cm}^{-1}\right)$ vibrations were non-existent for pc-A3A-pS4P,

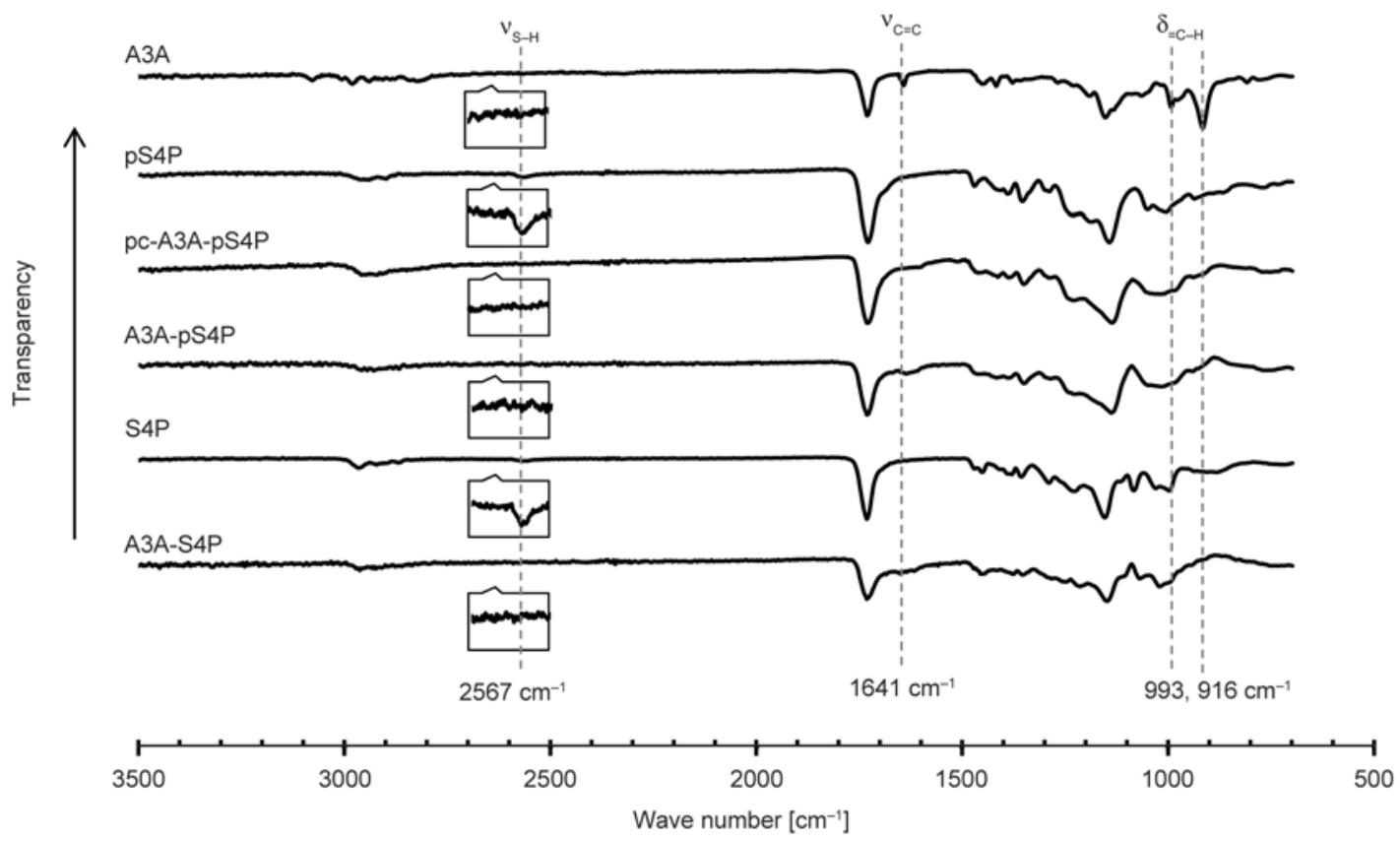

Figure 7. FT-IR spectra of pc-A3A-pS4P, A3A-pS4P and A3A-S4P compared with those of A3A, pS4P and S4P

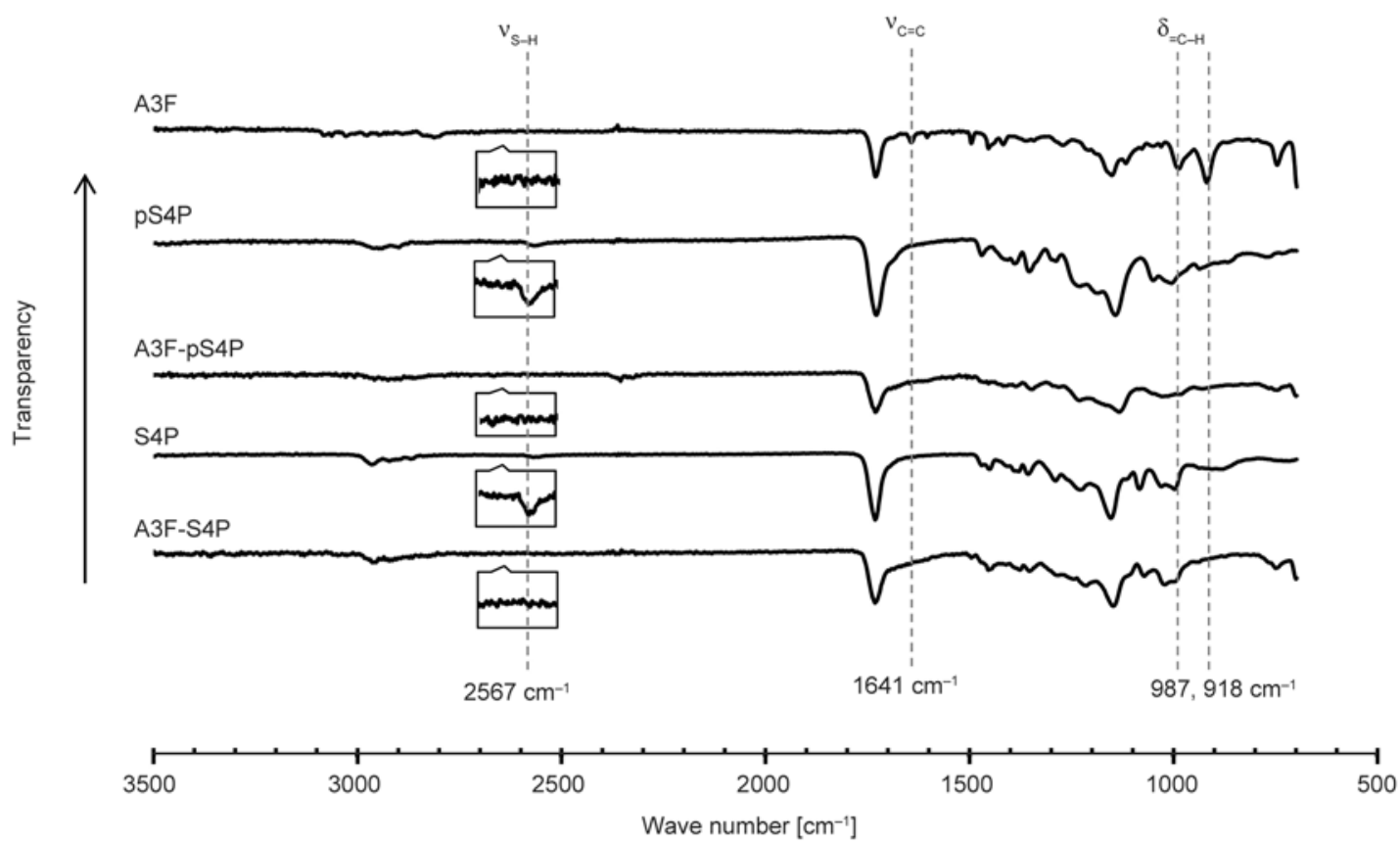

Figure 8. FT-IR spectra of A3F-pS4P and A3F-S4P compared with those of A3F, pS4P and S4P 
A3A-pS4P and A3A-S4P. Furthermore, an absorption band due to stretching vibration of S-H group $\left(v_{\mathrm{S}-\mathrm{H}}\right)$ at $2567 \mathrm{~cm}^{-1}$ which was observed in a longitudinally enlarged spectrum at the wavelength region from 2500 to $2700 \mathrm{~cm}^{-1}$ for $\mathrm{pS} 4 \mathrm{P}$ or S4P was nonexistent for all the cured resins. These results indicate that thiol-ene reaction between allyl and thiol groups almost completely progressed. Although pcA3A-pS4P was a heterogeneous film with many wrinkles, the thiol-ene photopolymerization considerably proceeded. In a similar manner, smooth progress of thiol-ene thermal polymerizations of $\mathrm{A} 3 \mathrm{~F}$ with pS4P and S4P was also confirmed, as is obvious from Figure 8. However, the fact that A3F did not produce a fully crosslinked film by thiol-ene photopolymerization suggests that the phenyl group of $\mathrm{A} 3 \mathrm{~F}$ hinders the photopolymerization at room temperature. Thermal and mechanical properties of the homogeneous film of thermally cured $\mathrm{A} 3 \mathrm{~A}$ or $\mathrm{A} 3 \mathrm{~F}$ with pS4P or S4P were investigated in the next section.

\subsection{Properties of thermally cured films}

Table 1 summarizes the values of $D_{\mathrm{s}}$ for all the thermally cured films dipped in acetone, DMF or water for $48 \mathrm{~h}$. As A3A, A3F, pS4P and S4P are soluble in DMF and acetone, the fact that all the films swelled in the solvents indicates the formation of polymer network. However, the solvents after swelling tests were slightly colored yellow only for A3A-S4P and A3F-S4P in acetone and DMF, suggesting that incompletely crosslinked polymers are slightly formed for the S4P-based cured resins. It is inferred that some side-reactions disturbing the crosslinking reaction occurred because of a lower reactivity of secondary thiol groups of S4P than that of primary thiol groups of $\mathrm{pS} 4 \mathrm{P}$, considering that thiol and allyl groups were almost completely consumed for A3AS4P and A3F-S4P as is obvious from the FT-IR analysis. If the crosslinking density of S4P-based cured resin is lower than that of pS4P-based cure resin, the $D_{\mathrm{s}}$ of the former resin would be higher than

Table 1. $D_{\mathrm{s}}$ values [\%] of A3A-pS4P, A3A-S4P, A3F-pS4P and $\mathrm{A} 3 \mathrm{~F}-\mathrm{S} 4 \mathrm{P}$ films dipped in acetone, DMF or water at room temperature for $48 \mathrm{~h}$

\begin{tabular}{|l|c|c|c|}
\hline \multicolumn{1}{|c|}{ Sample } & Acetone & DMF & Water \\
\hline A3A-pS4P & 30.8 & 109.2 & 2.0 \\
\hline A3A-S4P & 33.0 & 109.0 & 1.9 \\
\hline A3F-pS4P & 25.7 & 138.9 & 1.5 \\
\hline A3F-S4P & 21.1 & 119.5 & 3.2 \\
\hline
\end{tabular}

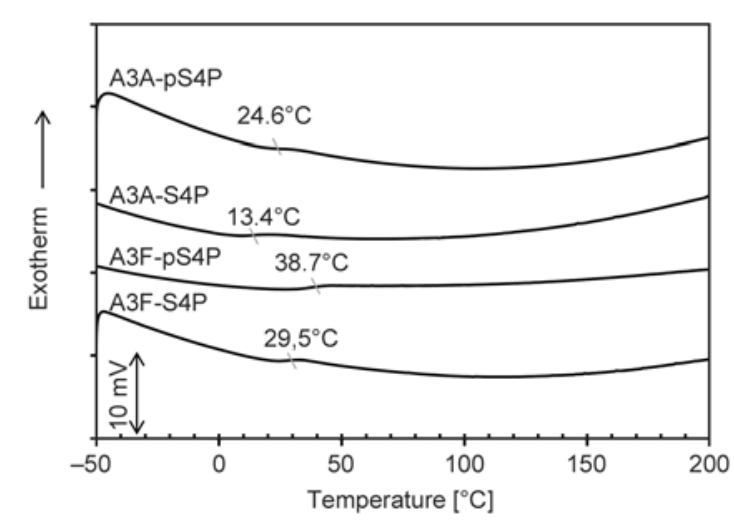

Figure 9. DSC curves of A3A-pS4P, A3A-S4P, A3F-pS4P and A3F-S4P

that of the latter. However, the $D_{\mathrm{s}}$ values of S4P-based cured resins in acetone or DMF were not always larger than those for the corresponding pS4P-based cured resin. This result may be caused by some elution of incompletely crosslinked polymers. The order of a higher $D_{\mathrm{s}}$ value by a difference of dipped solvent was DMF > acetone > water, indicating that the hydrophilicity of the formed polymer network is not so large in agreement with a hydrophobic character of other parts of the polymer network than amino acid residues.

Figure 9 shows the DSC charts of all the thermally cured resins. Every cured resin showed only a $T_{\mathrm{g}}$ at a temperature region from 13 to $39^{\circ} \mathrm{C}$, suggesting that the cured resin is amorphous polymer. The $T_{\mathrm{g}} \mathrm{s}$ of A3F-pS4P and A3F-S4P $\left(38.7\right.$ and $\left.29.5^{\circ} \mathrm{C}\right)$ were higher than those of A3A-pS4P and A3A-S4P (24.6 and $13.4^{\circ} \mathrm{C}$ ), attributable to the fact that the former networks have bulky benzyl groups leading to suppression of thermal motion of the polymer chain. Also, $T_{\mathrm{g}} \mathrm{s}$ of A3A-pS4P and A3F-pS4P (24.6 and $38.7^{\circ} \mathrm{C}$ ) were higher than those of A3A-S4P and A3F-S4P $\left(13.4\right.$ and $\left.29.5^{\circ} \mathrm{C}\right)$, respectively. The possibility that S4P-based cured resin has a lower crosslinking density than pS4P-based resin does is also supported from this DSC result.

Figure 10 shows TGA curves of all the cured resins. The $T_{5} \mathrm{~s}$ of A3F-pS4P and A3F-S4P (282.0 and $266.2^{\circ} \mathrm{C}$ ) were higher than those of A3A-pS4P and A3A-S4P $\left(258.1\right.$ and $\left.257.6^{\circ} \mathrm{C}\right)$, respectively. This result is attributable to a higher thermal stability of phenylalanine than alanine residue. Also, $T_{5} \mathrm{~S}$ of A3A-pS4P and A3F-pS4P $\left(258.1\right.$ and $\left.282.0^{\circ} \mathrm{C}\right)$ were a little higher than those of A3A-S4P and A3F-S4P $\left(257.6\right.$ and $\left.266.2^{\circ} \mathrm{C}\right)$, respectively. Furthermore, the char yields at ca. $500^{\circ} \mathrm{C}$ for $\mathrm{A} 3 \mathrm{~A}-\mathrm{pS} 4 \mathrm{P}$ and $\mathrm{A} 3 \mathrm{~F}-$ pS4P were higher than those for A3A-S4P and A3F- 


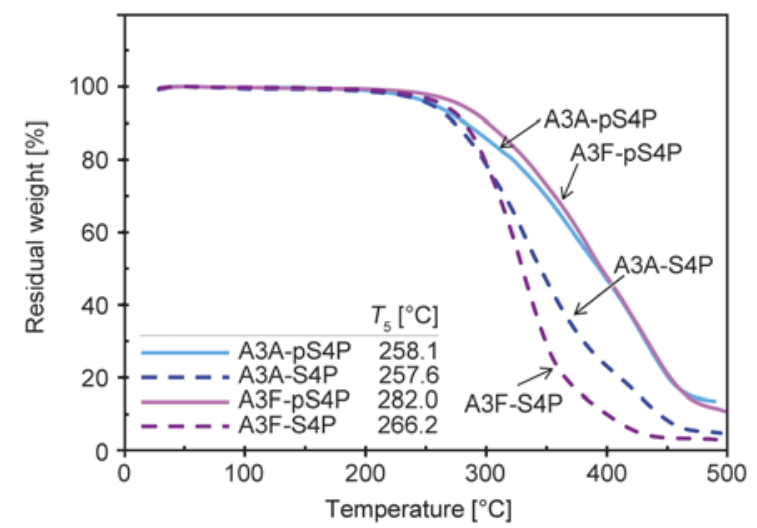

Figure 10. TGA curves of A3A-pS4P, A3A-S4P, A3F-pS4P and A3F-S4P

S4P. These results may be caused by a little higher crosslinking density of the polymer network from pS4P than that from S4P, considering that the crosslinkage prevents the formation of volatile lowmolecular-weight fragments even if some bonds of the main chain were cleaved. The $T_{5} \mathrm{~S}$ of A3A-S4P and $\mathrm{A} 3 \mathrm{~F}-\mathrm{S} 4 \mathrm{P}$ were comparable to those of polymer networks prepared by the thiol-ene photopolymerizations of S4P and allyl-etherified trehaloses with degrees of allylation of ca. 6 and 8 (251.4 and $289.4^{\circ} \mathrm{C}$ ), respectively, indicating that the amino acid moiety has a similar thermal stability to the saccharide moiety [43]. However the $T_{5} \mathrm{~s}$ were lower than that $\left(343.9^{\circ} \mathrm{C}\right)$ of the polymer network prepared by the thiol-ene photoplymerization of S4P and allyl-etherified eugenol (AEG) [44], indicating that the amino acid moiety has lower thermal stability than eugenol moiety.

Figure 11 shows typical stress-strain curves by a tensile mode for A3A-pS4P, A3A-S4P, A3F-pS4P and A3F-S4P. It is obvious that a maximal stress of A3F-based cured resin is much higher than that of A3A-based cured resin, and that a strain at break of

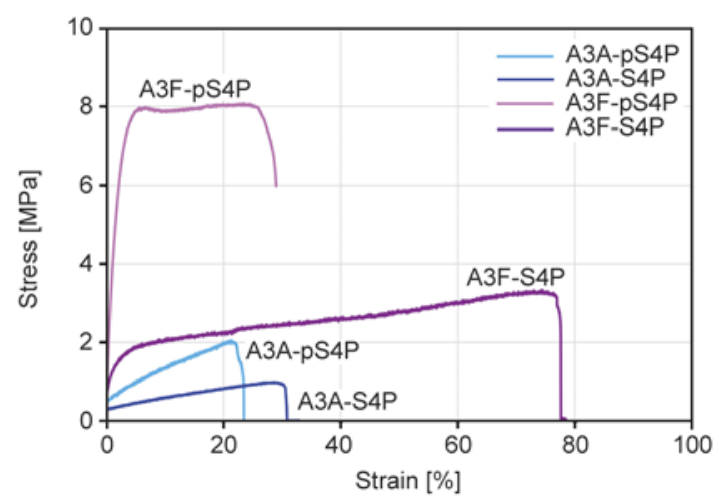

Figure 11. Stress-strain curves of A3A-pS4P, A3A-S4P, A3F-pS4P and A3F-S4P
Table 2. Tensile properties of A3A-pS4P, A3A-S4P, A3FpS4P and A3F-S4P

\begin{tabular}{|l|c|c|c|}
\hline \multicolumn{1}{|c|}{ Sample } & $\begin{array}{c}\text { Tensile } \\
\text { strength } \\
{[\mathbf{M P a}]}\end{array}$ & $\begin{array}{c}\text { Tensile } \\
\text { modulus } \\
{[\mathbf{M P a}]}\end{array}$ & $\begin{array}{c}\text { Elongation at } \\
\text { break } \\
{[\%]}\end{array}$ \\
\hline A3A-pS4P & $2.14 \pm 0.67$ & $7.39 \pm 1.42$ & $25.2 \pm 6.0$ \\
\hline A3A-S4P & $1.02 \pm 0.51$ & $3.90 \pm 1.00$ & $27.6 \pm 6.6$ \\
\hline A3F-pS4P & $9.48 \pm 2.02$ & $406 \pm 129$ & $15.9 \pm 8.6$ \\
\hline A3F-S4P & $3.02 \pm 0.66$ & $66.5 \pm 55.8$ & $71.8 \pm 9.1$ \\
\hline
\end{tabular}

S4P-based cured resin is higher than that of pS4Pbased cured resin. Table 2 summarizes tensile strength, modulus and elongation at break of the cured resins. Tensile strengths and moduli of A3FpS4P and A3F-S4P were much higher than those of A3A-pS4P and A3A-S4P, respectively. Especially, the former had much higher tensile moduli than the latter, attributable to the fact that the former network is in glassy state at room temperature, while the latter is in rubbery state, as is obvious from their $T_{\mathrm{g}} \mathrm{s}$. Also, tensile strengths and moduli of A3A-pS4P and A3F-pS4P were higher than those of A3A-S4P and A3F-S4P, respectively. Reversely, the latter displayed higher elongation at break than the former, suggesting that S4P-based polymer network has a lower crosslinking density than pS4P-based polymer network does. Consequently, A3F-pS4P exhibited the highest tensile strength and modulus (9.48 and $406 \mathrm{MPa}$ ), whose values were much higher than those of the already reported AEG-pS4P $(0.98$ and $23.9 \mathrm{MPa}$ ) [44]. The difference in the mechanical properties should be caused by the fact that the allyl functionality of A3F (3) is higher than that of AEG (2), leading to a higher crosslinking density.

\section{Conclusions}

Both $C$ - and $N$-terminal allylated amino acid derivatives, $\mathrm{A} 3 \mathrm{~A}$ and $\mathrm{A} 3 \mathrm{~F}$ were conveniently synthesized by one-pot reactions of L-alanine and L-phenylalanine with allyl bromide in the presence of sodium hydroxide, respectively. Thiol-ene thermal polymerization of A3A or A3F with $\mathrm{pS} 4 \mathrm{P}$ or S4P at allyl/SH $1 / 1$ produced a homogeneous and flat film (A3ApS4P, A3A-S4P, A3F-S4P or A3F-S3I), while the corresponding photo-curing did not give a successful result. Although all the thermally cured films swelled in acetone, DMF and water, some elution of incompletely crosslinked polymers was observed for the S4P-based cured resins. A higher order of $D_{\mathrm{s}}$ for each cured film was DMF $>$ acetone $>$ water. The $T_{\mathrm{g}} \mathrm{S}$ $\left(38.7\right.$ and $29.5^{\circ} \mathrm{C}$ ) of A3F-pS4P and A3F-S4P were 
higher than those $\left(24.6\right.$ and $\left.13.4^{\circ} \mathrm{C}\right)$ of $\mathrm{A} 3 \mathrm{~A}-\mathrm{pS} 4 \mathrm{P}$ and A3A-S4P, respectively. The $T_{5} \mathrm{~S}(282.0$ and $266.2^{\circ} \mathrm{C}$ ) of A3F-pS4P and A3F-S4P were higher than those $\left(258.1\right.$ and $\left.257.6^{\circ} \mathrm{C}\right)$ of $\mathrm{A} 3 \mathrm{~A}-\mathrm{pS} 4 \mathrm{P}$ and A3A-S4P, respectively. A3F- and pS4P-based cured resins exhibited much higher tensile strengths and moduli than $\mathrm{A} 3 \mathrm{~A}-$ and S4P-based cured resins, respectively. A3F-pS4P displayed the highest $T_{5}$ $\left(282.0^{\circ} \mathrm{C}\right)$, tensile strength $(9.5 \mathrm{MPa})$ and modulus (406 MPa) among all the cured resins. Biodegradability and biocompatibility of these materials are currently under consideration. The methodology in this study is expected to be applied to the preparation of various amino acid-incorporated polymer networks which are applicable to biomaterials.

\section{Acknowledgements}

We gratefully acknowledge financial support from the Chiba Institute of Technology. We thank Mr. Shohei Nagashima of our department for his helpful suggestions.

\section{References}

[1] Lokitz B. S., York A. W., Stempka J. E., Treat N. D., Li Y., Jarrett W. L., McCormick C. L.: Aqueous RAFT synthesis of micelle-forming amphiphilic block copolymers containing $N$-acryloylvaline. Dual mode, temperature $/ \mathrm{pH}$ responsiveness, and 'locking' of micelle structure through interpolyelectrolyte complexation. Macromolecules, 40, 6473-6480 (2007).

DOI: $10.1021 / \mathrm{ma} 070921 \mathrm{v}$

[2] Lokitz B. S., Convertine A. J., Ezell R. G., Heldenreich A., Li Y., McCormick C. L.: Responsive nanoassemblies via interpolyelectrolyte complexation of amphiphilic block copolymer micelles. Macromolecules, 39, 8594-8602 (2006).

DOI: $10.1021 / \mathrm{ma} 061672 \mathrm{y}$

[3] Oishi T., Lee Y-K., Nakagawa A., Onimura K., Tsutsumi H. J.: Syntheses and polymerizations of novel chiral poly(acrylamide) macromonomers and their chiral recognition abilities. Journal of Polymer Science Part A: Polymer Chemistry, 40, 1726- 1741 (2002). DOI: $10.1002 /$ pola. 10250

[4] Barbucci R., Casolaro M., Magnani A.: The role of poly electrolytes in the permeability control of insulin: Behavior of poly $(N$-acryloyl-glycine) grafted on porous cellulose membrane. Journal of Controlled Release, 17, 79-88 (1991). DOI: 10.1016/0168-3659(91)90133-X

[5] Xu H., Yao Q., Cai C., Gou J., Zhang Y., Zhong H., Tang X.: Amphiphilic poly(amino acid) based micelles applied to drug delivery: The in vitro and in vivo challenges and the corresponding potential strategies. Journal of Controlled Release, 199, 84-97 (2015). DOI: $10.1016 /$ j.j.jconrel.2014.12.012
[6] Roy S. G., Acharya R., Chatterji U., De P.: RAFT polymerization of methacrylates containing a tryptophan moiety: Controlled synthesis of biocompatible fluorescent cationic chiral polymers with smart $\mathrm{pH}-$ responsiveness. Polymer Chemistry, 4, 1141-1152 (2013).

DOI: $10.1039 / \mathrm{c} 2 \mathrm{py} 20821 \mathrm{k}$

[7] Bauri K., Roy S. G., Pant S., De P.: Controlled synthesis of amino acid-based $\mathrm{pH}-$ responsive chiral polymers and self-assembly of their block copolymers. Langmuir, 29, 2764-2774 (2013).

DOI: $10.1021 / 1 \mathrm{a} 304918 \mathrm{~s}$

[8] Bauri K., Pant S., Roy S. G., De P.: Dual pH and temperature responsive helical copolymer libraries with pendant chiral leucine moieties. Polymer Chemistry, 4, 4052-4060 (2013).

DOI: $10.1039 / \mathrm{c} 3$ py00434a

[9] Bauri K., De P.: Polyisobutylene-based helical block copolymers with $\mathrm{pH}$-responsive cationic side-chain amino acid moieties by Tandem living polymerizations. Macromolecules, 46, 5861-5870 (2013). DOI: $10.1021 / \mathrm{ma} 401395 \mathrm{f}$

[10] Luo C., Zhao B., Li Z.: Dual stimuli-responsive polymers derived from $\alpha$-amino acids: Effects of molecular structure, molecular weight and end-group. Polymer, 53, 1725-1732 (2012).

DOI: $10.1016 /$ j.polymer.2012.02.032

[11] Luo C., Liu Y., Li Z.: Thermo- and pH-responsive polymer derived from methacrylamide and aspartic acid. Macromolecules, 43, 8101-8108 (2010). DOI: $10.1021 / \mathrm{ma} 1015227$

[12] Mori H., Kato I., Matsuyama M., Endo T.: RAFT polymerization of acrylamides containing proline and hydroxyproline moiety: Controlled synthesis of watersoluble and thermoresponsive polymers. Macromolecules, 41, 5604-5615 (2008).

DOI: $10.1021 / \mathrm{ma} 800181 \mathrm{~h}$

[13] Lu A., Smart T. P., Epps T. H., Longbottom D. A., O'Reilly R. K.: L-proline functionalized polymers prepared by raft polymerization and their assemblies as supported organocatalysts. Macromolecules, 44, 72337241 (2011).

DOI: $10.1021 / \mathrm{ma} 201256 \mathrm{~m}$

[14] Skey J., Willcock H., Lammens M., Prez F. D., O’Reilly R. K.: Synthesis and self-assembly of amphiphilic chiral poly(amino acid) star polymers. Macromolecules, 43, 5949-5955 (2010). DOI: $10.1021 / \mathrm{ma101019g}$

[15] Klok H-A., Langenwalter J. F., Lecommandoux S.: Selfassembly of peptide-based diblock oligomers. Macromolecules, 33, 7819-7826 (2000).

DOI: $10.1021 / \mathrm{ma} 0009606$

[16] Mori H., Kato I., Saito S., Endo T.: Proline-based block copolymers displaying upper and lower critical solution temperatures. Macromolecules, 43, 1289-1298 (2010). DOI: $10.1021 / \mathrm{ma902002b}$ 
[17] Skey J., Hansell C. F., O’Reilly R. K.: Stabilization of amino acid derived diblock copolymer micelles through favorable D:L side chain interactions. Macromolecules, 43, 1309-1318 (2010).

DOI: $10.1021 / \mathrm{ma} 902356 \mathrm{u}$

[18] Mori H., Matsuyama M., Sutoh K., Endo T.: RAFT polymerization of acrylamide derivatives containing Lphenylalanine moiety. Macromolecules, 39, 4351-4360 (2006).

DOI: $10.1021 / \mathrm{ma} 052756 \mathrm{u}$

[19] Sanda F., Nakamura M., Endo T.: Syntheses and radical copolymerization behavior of optically active methacrylamides having L- and D-leucine moieties. Interaction between L- and D-forms. Macromolecules, 29, 80648068 (1996).

DOI: $10.1021 / \mathrm{ma} 960906 \mathrm{i}$

[20] Casolaro M.: Vinyl polymers containing L-valine and L-leucine residues: Thermodynamic behavior of homopolymers and copolymers with $\mathrm{N}$-isopropylacrylamide. Macromolecules, 28, 2351-2358 (1995).

DOI: $10.1021 / \mathrm{ma} 00111 \mathrm{a} 031$

[21] Sanda F., Nakamura M., Endo T., Takata T., Handa H.: Synthesis of novel optically active polymethacrylamide having L-leucine structure in the side chain. Macromolecules, 27, 7928-7929 (1994).

DOI: $10.1021 / \mathrm{ma} 00104 \mathrm{a} 059$

[22] Safranj A., Yoshida M., Omichi H., Katakai R.: Surfactant effect on the inverse volume phase transition of a polymer with amino acid side chains. Langmuir, 9, 3338-3340 (1993).

DOI: $10.1021 / 1 \mathrm{a} 00036 \mathrm{a} 003$

[23] Roy S. G., Haldar U., De P.: Remarkable swelling capability of amino acid based cross-linked polymer networks in organic and aqueous medium. ACS Applied Materials and Interfaces, 6, 4233-4241 (2014).

DOI: $10.1021 / \mathrm{am} 405932 \mathrm{f}$

[24] Roy S. G., De P.: Swelling properties of amino acid containing cross-linked polymeric organogels and their respective polyelectrolytic hydrogels with $\mathrm{pH}$ and salt responsive property. Polymer, 55, 5425-5434 (2014). DOI: $10.1016 /$ j.polymer.2014.08.072

[25] Kumar S., Roy S. G., De P.: Cationic methacrylate polymers containing chiral amino acid moieties: Controlled synthesis via RAFT polymerization. Polymer Chemistry, 3, 1239-1248 (2012).

DOI: $10.1039 / \mathrm{c} 2$ py00607c

[26] Sun H., Gao C.: Facile synthesis of multiamino vinyl poly(amino acid)s for promising bioapplications. Biomacromolecules, 11, 3609-3616 (2010).

DOI: $10.1021 / \mathrm{bm} 101060 \mathrm{~m}$

[27] Adams D. J., Atkins D., Cooper A. I., Furzeland S., Trewin A., Young I.: Vesicles from peptidic side-chain polymers synthesized by atom transfer radical polymerization. Biomacromolecules, 9, 2997-3003 (2008). DOI: $10.1021 / \mathrm{bm} 8006693$
[28] Obeid R., Scholz C.: Synthesis and self-assembly of well-defined poly(amino acid) end-capped poly(ethylene glycol) and poly(2-methyl-2-oxazoline). Biomacromolecules, 12, 3797-3804 (2011).

DOI: $10.1021 / \mathrm{bm} 201048 \mathrm{x}$

[29] Hadjichristidis N., Iatrou H., Pitsikalis M., Sakellariou G.: Synthesis of well-defined polypeptide-based materials via the ring-opening polymerization of $\alpha$-amino acid $N$-carboxyanhydrides. Chemical Reviews, 109, 5528-5578 (2009).

DOI: $10.1021 / \mathrm{cr} 900049 \mathrm{t}$

[30] Lu H., Cheng J.: Hexamethyldisilazane-mediated controlled polymerization of $\alpha$-amino acid $N$-carboxyanhydrides. Journal of the American Chemical Society, 46, 14114-14115 (2007). DOI: $10.1021 / \mathrm{ja} 074961 \mathrm{q}$

[31] Mallakpour S., Khani M.: Construction of chiral polyesters from polycondensation of multifunctional monomer containing both flexible amino acid and rigid pendant groups with aromatic diols. Amino Acids, 39, 841-848 (2010). DOI: $10.1007 / \mathrm{s} 00726-010-0539-\mathrm{x}$

[32] Blocher M., Liu D., Luisi L.: Liposome-assisted selective polycondensation of $\alpha$-amino acids and peptides: The case of charged liposomes. Macromolecules, 33, 5787-5796 (2000).

DOI: $10.1021 / \mathrm{ma} 000540 \mathrm{~g}$

[33] Kiyotsukuri T., Nagata M., Kitazawa T., Tsutsumi N.: Synthesis of polymers from $\alpha$-amino acids by polyaddition. European Polymer Journal, 27, 183-186 (1992). DOI: 10.1016/0014-3057(92)90305-L

[34] Li Y., Xiao F., Moon K-S., Wong C. P.: Novel curing agent for lead-free electronics: Amino acid. Journal of Polymer Science Part A: Polymer Chemistry, 44, 10201027 (2006). DOI: $10.1002 /$ pola.21239

[35] Li Y., Xiao F., Wong C. P.: Novel, environmentally friendly crosslinking system of an epoxy using an amino acid: Tryptophan-cured diglycidyl ether of bisphenol A epoxy. Journal of Polymer Science Part A: Polymer Chemistry, 45, 181-190 (2007). DOI: $10.1002 /$ pola.21742

[36] Ozawa Y., Shibata M.: Biobased thermosetting resins composed of L-lysine methyl ester and bismaleimide. Journal of Applied Polymer Science, 131, 40379/140379/8 (2014).

DOI: $10.1002 / a p p .40379$

[37] Lowe A. B.: Thiol-ene 'click' reactions and recent applications in polymer and materials synthesis: A first update. Polymer Chemistry, 5, 4820-4870 (2014). DOI: $10.1039 / \mathrm{C} 4 \mathrm{PY} 00339 \mathrm{~J}$

[38] Lowe A. B.: Thiol-ene 'click' reactions and recent applications in polymer and materials synthesis. Polymer Chemistry, 1, 17-36 (2010). DOI: $10.1039 / \mathrm{b} 9$ py00216b 
[39] Dondoni A.: The emergence of thiol-ene coupling as a click process for materials and bioorganic chemistry. Angewandte Chemie International Edition, 47, 89958997 (2008).

DOI: $10.1002 /$ anie. 200802516

[40] Morgan C. R., Magnotta F., Ketley A. D.: Thiol/ene photocurable polymers. Journal of Polymer Science: Polymer Chemistry Edition, 15, 627-645 (1977).

DOI: 10.1002/pol.1977.170150311

[41] Echeverri D. A., Cádiz V., Ronda J. C., Rios L. A.: Synthesis of elastomeric networks from maleated soybean-oil glycerides by thiol-ene coupling. European Polymer Journal, 48, 2040-2049 (2012).

DOI: $10.1016 /$ j.eurpolymj.2012.09.004

[42] Ortiz R. A., Martinez A. Y. R., Valdez A. E. G., Duarte M. L. B.: Preparation of a crosslinked sucrose polymer by thiol-ene photopolymerization using dithiothreitol as comonomer. Carbohydrate Polymers, 82, 822-882 (2010).

DOI: $10.1016 /$ j.carbpol.2010.05.054
[43] Nagashima S., Shimasaki T., Teramoto N., Shibata M.: Trehalose-incorporated polymer network by thiol-ene photopolymerization. Polymer Journal, 46, 728-735 (2014) DOI: $10.1038 /$ pj.2014.53

[44] Yoshimura T., Shimasaki T., Teramoto N., Shibata M.: Bio-based polymer networks by thiol-ene photopolymerizations of allyl-etherified eugenol derivatives. European Polymer Journal, in press (2015). DOI: $10.1016 /$ j.eurpolymj.2014.11.013

[45] Karmann L., Kazmaier U.: Thiol-ene click reactions Versatile tools for the modification of unsaturated amino acids and peptides. European Journal of Organic Chemistry, 31, 7101-7109 (2013). DOI: $10.1002 /$ ejoc.201300672

[46] Tang W., Becker M.: 'Click’ reactions: A versatile toolbox for the synthesis of peptide-conjugates. Chemical Society Reviews, 43, 7013-7039 (2014). DOI: $10.1039 / \mathrm{c} 4 \mathrm{cs} 00139 \mathrm{~g}$ 